\title{
RANCANG BANGUN ALAT UKUR KADAR GAS CO BERBASIS NIRKABEL RF UNTUK PEMANTAUAN KONDISI PENCEMARAN UDARA
}

\author{
SRI SURYANINGSIH*, JAJAT YUDA MINDARA, SAHRUL HIDAYAT, IRMHA \\ CHAERUNNISA \\ Departemen Fisika Fakultas MIPA Universitas Padjadjaran, \\ Jl. Raya Bandung-Sumedang Km 21, Jatinangor 45363 \\ *email : sri@phys.unpad.ac.id
}

\begin{abstract}
Abstrak. Pencemaran gas karbon monoksida sebagai gas buang menigkat setiap tahun seiring dengan penigkatan jumlah pengguna kendaraan bermotor. Karbon monoksida memberi dampak yang membahayakan lingkungan dan kesehatan manusia bahkan berujung kematian. Pada penelitian ini telah diciptakan sebuah alat ukur gas $\mathrm{CO}$ dengan menggunakan sensor gas CO MQ-9 guna mendeteksi dan mengukur konsentrasi gas CO di udara. Perangkat ini menggunakan teknologi nirkabel RF sehingga dapat digunakan dari jarak jauh dan tidak membahayakan peneliti dari menghirup gas. Pengujian awal dilakukan dengan membandingkan besaran nilai yang dihasilkan alat ini dengan gas $\mathrm{CO}$ berkonsentrasi $0-1000 \mathrm{ppm}$. Dari hasil pengujian tersebut didapat tingkat kesalahan kalibrasi sebesar 22,83\%. Perangkat yang telah dikalibrasi kemudian diuji di lokasi yang berbeda untuk mendeteksi dan mengukur jumlah gas $\mathrm{CO}$ di lokasi tersebut. Hasil pengujian di beberapa lokasi, didapat data konsentrasi gas CO sebesar 1,89 ppm pada daerah yang tidak berpotensi adanya polusi dan $103,35 \mathrm{ppm}$ pada daerah yang berpotensi adanya polusi.
\end{abstract}

Kata kunci : gas CO, nirkabel RF, sensor gas CO MQ-9, konsentrasi gas

\begin{abstract}
Pollution of carbon monoxide gas as flue gas increased every year in line with the progressive increase in the number of users of motor vehicles. Carbon monoxide affects that harm the environment and human health even lead to death. In this research has created a $\mathrm{CO}$ gas measuring instrument by using $\mathrm{CO}$ gas sensor MQ-9 in order to detect and measure the concentration of $\mathrm{CO}$ gas in the air. This device uses RF wireless technology so it can be used remotely and does not endanger researchers from inhaling the gas. Initial testing is done by comparing the amount of the value generated by this device by the $\mathrm{CO}$ gas concentrating $0-1000 \mathrm{ppm}$. From these test results obtained calibration error rate of $22.83 \%$. The device that has been calibrated then tested at different locations to detect and measure the amount of $\mathrm{CO}$ gas at these locations. The test results in a few locations, data obtained $\mathrm{CO}$ gas concentration of 1.89 ppm in areas not potentially pollution and $103.35 \mathrm{ppm}$ to the area that has the potential pollution.
\end{abstract}

Keywords : CO gas, RF wireless, CO gas sensor MQ-9, gas concentration

\section{Pendahuluan}

Perkembangan teknologi yang semakin pesat mempengaruhi gaya hidup manusia menjadi terbiasa dengan proses kerja yang instan dan penggunaan produk-produk yang lebih kompleks. Salah satu contoh produk perkembangan teknologi adalah mobil, motor, dan berbagai macam jenis kendaraan bermotor lainnya. Tentunya semakin berkembangnya zaman, produksi kendaraan bermotor semakin meningkat dengan bertambahnya populasi manusia dan kebutuhan manusia akan 
pelayanan serba cepat. Namun, kerugian penggunaan kendaraan bermotor berbanding lurus dengan manfaat yang didapat dikarenakan gas buang kendaraan bermotor mengandung senyawa-senyawa kimia berbahaya yang berpengaruh pada pencemaran udara, salah satunya karbonmonoksida (CO). Carbon monoxide atau karbon monoksida (CO) adalah gas yang dihasilkan dari pembakaran tak sempurna dari gas alam dan bahan lain yang mengandung senyawa karbon seperti bensin, minyak tanah, minyak, propana, batubara, atau kayu. Karbon monoksida tidak berwarna, tidak berbau dan tidak berasa, sehingga secara tidak sadar manusia dapat menghirup gas ini melalui udara yang tercemar.

Gas CO juga dapat terbentuk dari kegiatan alam seperti gunung meletus atau gas beracun yang berasal dari alam. Selain bahayanya terhadap kesehatan manusia, gas CO juga menyebabkan pencemaran udara yang berefek buruk pada lingkungan hidup disekitarnya. Sensor gas dapat digunakan untuk mendeteksi gas yang berbeda mengandung $\mathrm{CO}$ dan gas mudah terbakar. Material sensitif dari sensor ini adalah $\mathrm{SnO}_{2}$ yang akan memiliki konduktivitas yang rendah saat di udara bersih. Konduktivitas sensor akan semakin meningkat seiring meningkatnya konsentrasi gas. Sensor biasa diaplikasikan untuk detektor kebocoran gas domestik, detektor gas industri, dan detektor gas portabel [1]. Pemantauan pengukuran nilai yang dihasilkan sensor akan ditampilkan secara langsung (real time) menggunakan sistem komunikasi nirkabel untuk mengirim dan menerima data secara langsung dan terus-menerus dari jarak jauh. Pada bagian penerima, gelombang pembawa yang mengandung data digital diterima oleh Radio Frequency FM dibagian penerima [2].

Dengan melihat banyaknya bahaya yang disebabkan gas CO maka tujuan dari penelitian membuat alat ukur pendeteksi konsentrasi gas $\mathrm{CO}$ untuk mengetahui kondisi pencemaran udara pada lingkungan. Namun dengan bahayanya gas CO terhadap tubuh manusia, maka diperlukan sebuah alat pendeteksi yang menggunakan teknologi nirkabel guna mendeteksi konsentrasi gas CO dari jarak jauh. Pemantauan pengukuran nilai yang dihasilkan sensor akan ditampilkan secara langsung (real time).

\section{Metode Penelitian}

Desain sistem alat ukur konsentrasi gas CO ini dibagi menjadi empat tahap. Tahap yang pertama persiapan alat dan bahan apa saja yang akan digunakan pada penelitian ini beserta fungsinya. Sensor gas $\mathrm{CO}$ menggunakan sensor gas tipe MQ-9, mikrokontroller menggunakan arduino nano yang dilengkapi dengan modul transmiter XD-FXT dan modul receiver CZS-3. Kedua adalah deskripsi perancangan perangkat keras dan lunak yang diawali dengan diagram blok rangkaian yang menjelaskan prinsip kerja rangkaian. Pembuatan perangkat lunak di Arduino menggunakan bahasa pemrograman C. Pembuatan perangkat lunak pada transmitter dan receiver ini dilaksanakan di IDE Arduino yang mempunyai fungsi sebagai editor, compiler dan uploader [3]. Arduino akan membaca hasil respon dan mengubah sinyal analog dari sensor menjadi sinyal digital sehingga dapat diterima transmitter dan dikirimkan ke receiver dari jarak jauh. Setelah rangkaian receiver menerima sinyal digital dari transmitter, arduino akan membaca sinyal digital dan meneruskan responnya secara real-time ke PC. Tahap ketiga adalah kalibrasi alat yang menjelaskan sistem kerja dari pengambilan data hasil kalibrasi rangkaian sensor CO. 
Pengukuran konsentrasi gas pada umumnya menggunakan alat ukur gas CO digital (CO meter), sehingga untuk mengetahui efektivitas dari sensor gas MQ-9 diperlukan perbandingan antara nilai konsentrasi gas ( $\mathrm{ppm}$ ) yang dihasilkan $\mathrm{CO}$ meter dan nilai data digital (n) dari sensor gas MQ-9. Pokok bahasan yang terakhir adalah uji alat ukur dengan menampilkan perubahan nilai konsentrasi gas CO. Pengujian alat ukur dilakukan dengan melakukan percobaan dan memonitor perubahan konsentrasi gas ( $\mathrm{ppm}$ ) tiap waktunya di beberapa tempat dengan keadaan berbeda yaitu pada daerah yang berpotensi berpolusi dan tidak berpolusi (non-polusi).

\section{Hasil dan Pembahasan}

Rangkaian transmitter yang telah dirancang terdiri dari sensor MQ-9, Arduino Nano dan transmitter board XD-FST. Kode program berhasil dicompile dan diupload yang ditandai dengan keterangan Done uploading. Hal ini menunjukkan bahwa kode program tidak ada kesalahan dan berhasil diupload ke port COM 4 yaitu port untuk rangkaian transmitter. Rangkaian receiver yang telah dirancang terdiri dari Arduino Nano dan receiver board CZS-3. Kode program dicompile dan diupload ke port COM3 yang merupakan rangkaian receiver. Hal ini ditandai dengan adanya keterangan Done uploading. Rangkaian receiver telah menerima respon data dari rangkaian transmitter dengan baik, hal ini ditunjukkan dengan tampilnya data-data yang muncul dalam periode yang sesuai dengan kode program yang telah dimasukkan. Lampu indilkator pada arduino menyala dan membuktikan bahwa rangkaian sudah terhubung dengan baik Gambar 1.
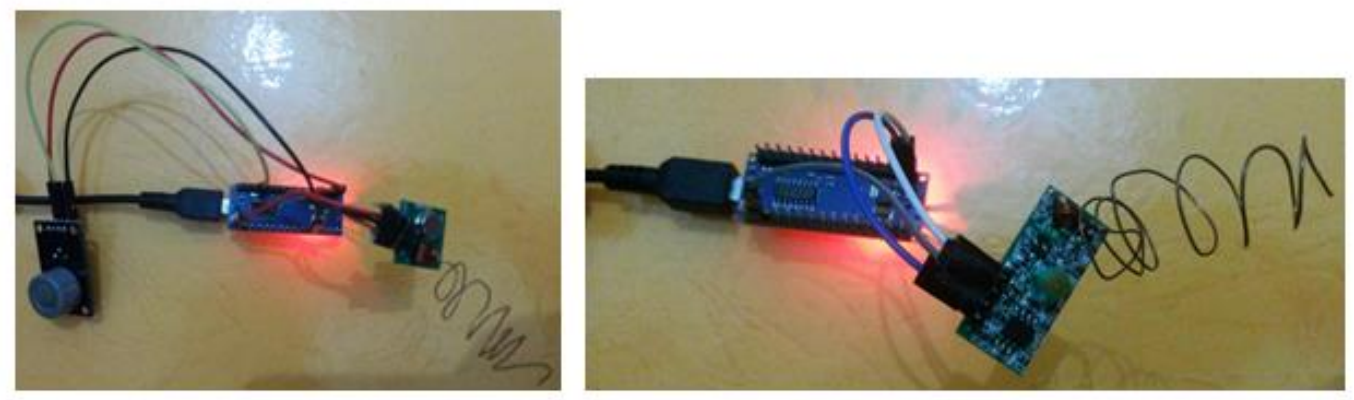

Gambar 1. Hasil perancangan rangkaian transmitter dan receiver

Nilai data keluaran juga meningkat cepat ketika sensor mendeteksi gas $\mathrm{CO}$, hal ini membuktikan bahwa sensor merespon dengan baik dan pengiriman data dengan komunikasi nirkabel berhasil dilakukan dengan cepat secara real time.

Pengkalibrasian alat dilakukan dengan membangun sistem kerja kalibrasi dengan memasang CO Meter (Lutron GCO-2008) dan rangkaian sensor CO MQ-9 pada sebuah chamber gas. Perubahan konsentrasi gas $\mathrm{CO}$ pada awal penurunan dari 1000 ppm mempunyai selisih sangat besar dan penurunan nilainya cukup cepat, begitu juga pada perubahan data digital. Pada saat konsentrasi gas mencapai kisaran 100 ppm, selisih perubahan nilai konsentrasi gas maupun data digital sangat kecil dan penurunan nilai terjadi cukup lambat. 


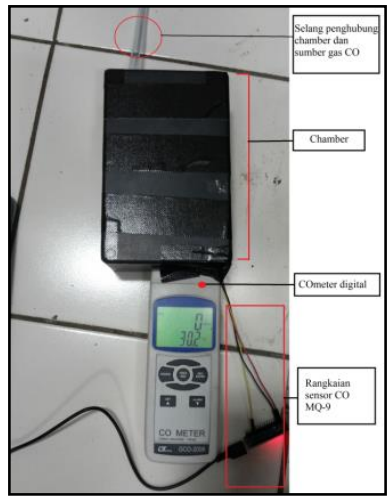

Gambar 2. Sistem Kerja Kalibrasi

Dengan menggunakan metode regresi linier, grafik hubungan konsentrasi gas dengan data digital akan menghasilkan suatu persamaan regresi berikut:

$$
\mathrm{Y}=4,4463 \mathrm{X}-337,02
$$

yang dapat digunakan untuk menjadi persamaan konversi pada alat sensor MQ-9 berupa nilai konversi dengan satuan ppm Gambar 3.

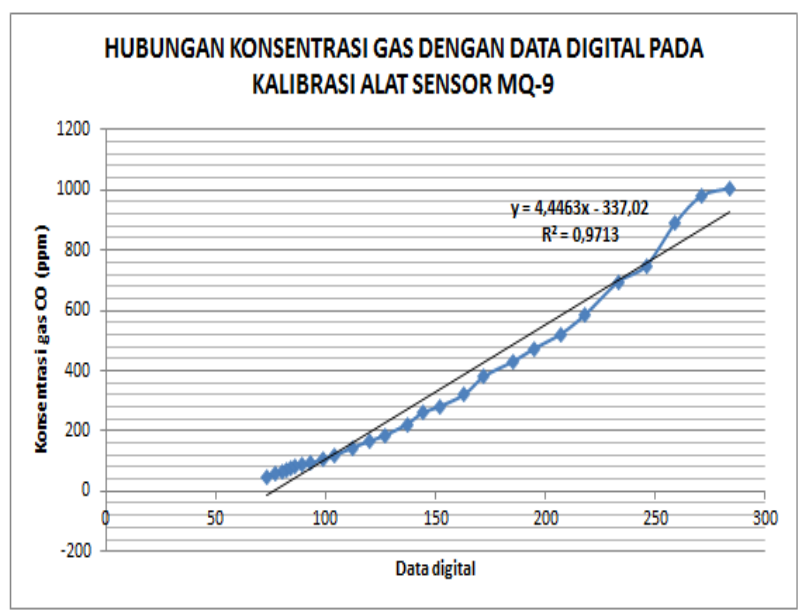

Gambar 3. Hubungan konsentrasi gas $\mathrm{CO}$ dengan data digital

Perbandingan konsentrasi gas $\mathrm{CO}(\mathrm{ppm})$ dan konsentrasi terkalibrasi (ppm) yang merupakan nilai konsentrasi yang dikonversi dengan persamaan (1).

Sesuai perbandingan dari kedua konsentrasi maka dapat dihitung tingkat kesalahan kalibrasi terhadap literatur melalui persamaan (2) [4].

$K S R=\left|\frac{P P M_{\text {kalibrasi }}-P P M_{\text {literatur }}}{P P M_{\text {literatur }}}\right| \times 100 \%$

Didapatkan tingkat kesalahan relatif rata-rata $22,83 \%$ untuk pengukuran konsentrasi gas $\mathrm{CO}$. Nilai kesalahan relatif ini cukup besar yang disebabkan perubahan data pada kisaran dibawah 100 ppm yang sangat kecil dibandingkan sebelumnya. 
Pengujian alat dilakukan guna mengetahui tingkat konsentrasi gas $\mathrm{CO}$ pada dua lokasi berbeda. Waktu pengujian selama 45 menit dengan interval waktu pengambilan data selama 1 menit.

Pada gambar 4 menunjukkan adanya kestabilan kadar CO dalam rentang 0 sampai 4 ppm yang menunjukkan keadaan normal pada daerah berpotensi tidak ada polusi udara. Konsentrasi tertinggi terjadi pada dua waktu dengan besar konsentrasi sebesar 8,89 ppm. Pada saat pengamatan, hal ini terjadi karena adanya kendaraan motor yang melewati lokasi pengambilan data.

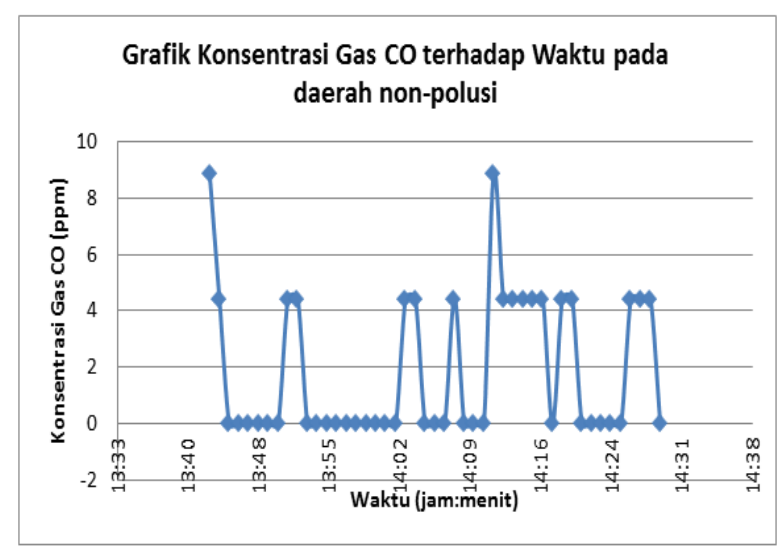

Gambar 4. Grafik konsentrasi gas CO terhadap waktu pada daerah non-polusi

Berdasarkan data konsentrasi gas $\mathrm{CO}$ yang didapat, rata-rata konsentrasi gas $\mathrm{CO}$ pada daerah ini adalah 1,89 ppm yang mana masih dalam kategori udara bersih walaupun adanya gas $\mathrm{CO}$.

Terlihat pada Gambar 5, konsentrasi gas CO pada daerah yang berpotensi terdapat polusi udara cukup besar dengan nilai yang selalu berubah-ubah tiap waktunya, hal ini disebabkan lalu lintas pada daerah tersebut sangat padat dikarenakan jam pulang kerja yang sudah biasa terjadi pada jam-jam tersebut. Banyaknya kendaraan bermotor yang melintasi jalan tidak dapat diprediksi jumlahnya sehingga nilai konsentrasi gas CO kerap berubah-ubah sesuai kondisi kepadatan kendaraan bermotor di lokasi.

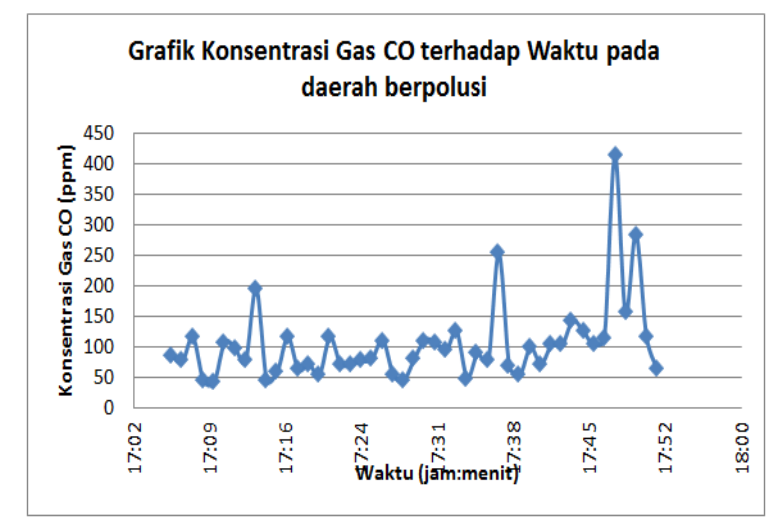

Gambar 5. Grafik konsentrasi gas CO terhadap waktu pada daerah berpolusi 
Konsentrasi gas CO tertinggi sebesar 413,43 ppm dan rata-rata konsentrasi gas CO sebesar 103,35 ppm, kondisi ini sudah merupakan kategori udara tercemar dan dapat membahayakan pengguna jalan dan sekitarnya jika terlalu lama menghirup gas CO pada daerah tersebut.

\section{Kesimpulan}

Telah berhasil dibuat alat ukur konsentrasi gas $\mathrm{CO}$ berbasis wireless RF yang terprogram oleh mikrokontroller Arduino dengan tingkat kesalahan relatif ratarata $22,83 \%$. Alat ukur dapat menghasilkan nilai keluaran konsentrasi $\mathrm{CO}$ pada lokasi tidak tercemar sebesar $1,89 \mathrm{ppm}$ dan 103,35 ppm pada lokasi yang berpolusi.

\section{Ucapan terima kasih}

Ucapan terima kasih pada pihak-pihak yang telah membantu secara substansi maupun finansial khususnya Laboratorium Energi Terbarukan dan Sistem Program Studi Fisika, FMIPA Unpad.

\section{Daftar Pustaka}

1. Noerhadi. Fikri. 2013. Sistem Pedometer dan Penghitung Detak Jantung Secara Nirkabel Berbasis Arduino. Universitas Indonesia. Depok.

2. Anonymous. MQ135 Semiconduct or Sensor for Air Quality Control. http://www.china-total.com/Product/meter/gas-sensor/MQ135.pdf.

3. Djuandi. Feri. 2011. Pengenalan Arduino. www.tobuku.com

4. Tooley. Michael. 2003. Rangkaian Elektronik : Prinsip dan Aplikasi. Erlangga. Jakarta. 